\title{
ANN model to predict the performance of parabolic dish collector with tubular cavity receiver
}

Reyhaneh Loni ${ }^{1,5}$, Alibakhsh Kasaeian ${ }^{2}$, Kazem Shahverdi $^{3,5}$, Ezzatollah Askari Asli-Ardeh ${ }^{1}$, Barat Ghobadian $^{4}$, and Mohammad H. Ahmadi ${ }^{2, *}$

${ }^{1}$ Department of Mechanics of Biosystem Engineering, University of Mohaghegh Ardabili, Ardabil, Iran

${ }^{2}$ Department of Renewable Energies, Faculty of New Sciences \& Technologies, University of Tehran, Tehran, Iran

${ }^{3}$ Department of Water Structures Engineering, Tarbiat Modares University, Tehran, Iran

${ }^{4}$ Department of Mechanics of Biosystem Engineering, Tarbiat Modares University, Tehran, Iran

${ }^{5}$ Young Researchers and Elites Club, Science and Research Branch, Islamic Azad University, Tehran, Iran

Received: 13 October 2016 / Accepted: 16 March 2017

\begin{abstract}
In this study, the thermal performance of a parabolic dish concentrator with a rectangular-tubular cavity receiver was investigated. The thermal oil was used as the working fluid in the solar collector system. The performance of the cavity receiver was studied in two ways as a numerical modeling method and the artificial neural networks (ANNs) methodology. In this study, three variable parameters including the different tube diameters equal to $5,10,22$, and $35 \mathrm{~mm}$, and different cavity depths equal to $0.5 a, 0.75 a, 1 a, 1.5 a$, and $2 a$ were considered. The purpose of this study is the prediction of the thermal performance of the cavity receiver in different amounts of solar irradiance, the cavity depth, and the diameter of tube by the ANN methodology. The main benefit of the ANN method, in comparison with the numerical modeling method, is the calculation time and cost saving. The results reveal that the ANN method can accurately predict the thermal performance of the cavity receiver at different variable parameters of the cavity depth, and tube diameter with $R^{2}=0.99$ for each prediction.
\end{abstract}

Keywords: ANN methodology / solar cavity receiver / thermal performance prediction

\section{Introduction}

Today, the attention on the renewable energy technologies as an alternative technology for fossil fuel, has increased. This is because of advantages of the renewable energy such as clean, no pollution, reproducible, and environmental friendly manner [1]. Parabolic dish concentrator with cavity receiver is investigated as a high efficiency technology for converting solar radiation to the thermal energy that can be used for heating, cooking, and producing electricity or mechanical work. The cavity receivers can absorb the maximum concentrator flux with the minimum heat losses [2].

The concentrated solar irradiation is came into the cavity receiver then hitted to the inner tube walls of the cavity receiver. The hit solar irradiation is absorbed by the working fluid that flows in the inner tube of the cavity receiver. The thermal losses of the cavity included (i) the reflection and emission of radiation from the inner surfaces of the cavity receiver outwards through its aperture, (ii) convection through the aperture of the cavity receiver, and (iii) the conduction heat losses through the walls and

\footnotetext{
* e-mail: mohammadhosein.ahmadi@gmail.com
}

receiver insulation [2]. The heat losses from a cavity receiver have an important effect on the thermal performance of the solar collector system. Consequently, minimizing of the heat losses in the cavity receiver is an effective way for improving the thermal performance of the cavity receiver. For this reason the optimization of the cavity receiver will be important for increasing the amount of the absorbing solar energy with minimum heat losses.

There are many significant researches on the cavity receiver system, e.g. [3-6]. Clausing [3] numerically studied on the convective heat loss of a large cubical cavity receiver. They investigated the effects of convection heat loss due to natural and forced convection. Le Quere et al. [4] proposed an experimental correlation of the Nusselt number for a cubical cavity under different angles of inclination. Harris and Lenz [2] theoretically studied the thermal efficiency of the cavity receiver in the different shapes. Huang et al. [5] analytically studied on the spherical shape of the cavity receiver. They concluded that the parabolic dish concentrator with cavity spherical receiver has $20 \%$ higher thermal performance more than solar trough performance. Le Roux et al. [6] investigated the optimization of the rectangular cavity receiver as a heat source of a Brytone cycle, while the air was used as the working fluid of the thermodynamic cycle. 


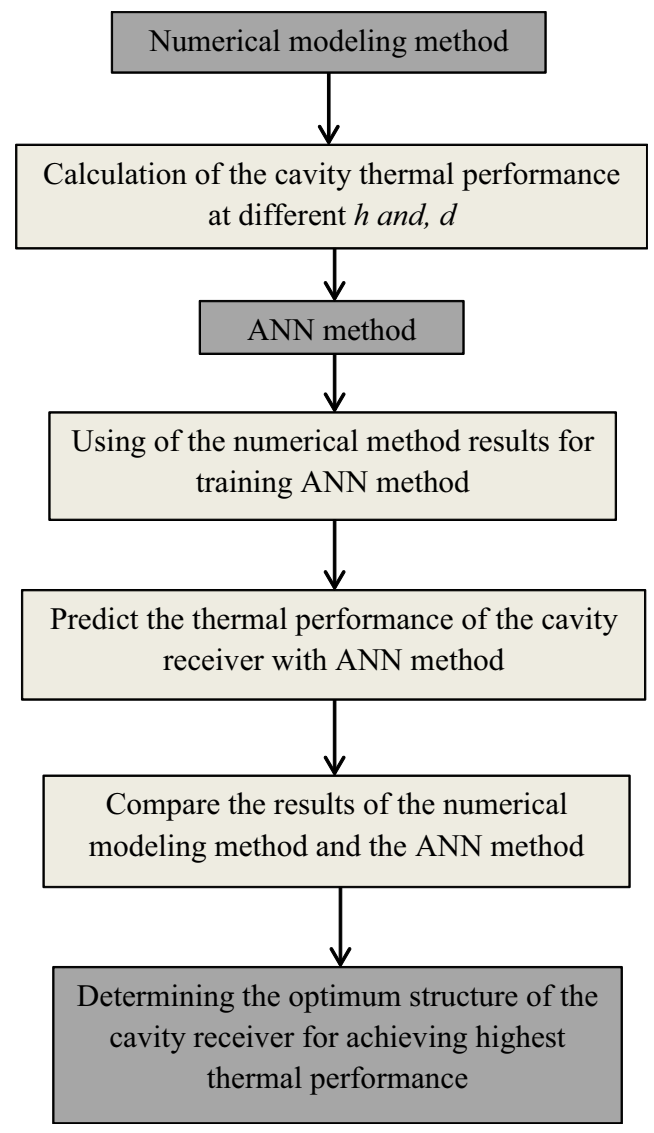

Fig. 1. The procedure of determining the optimum structure of cavity receiver.

On the other hand, artificial neural networks (ANNs) methodology is applied for modeling of the complex system performances, such as solar power systems. The ANN is used for modeling and simulation of the solar power systems, prediction of their performances, and optimization of their design or their operation condition. There are some studies that investigated the application of the ANNs methodology on the renewable energies, e.g. [7-14]. Kalogirou et al. [7] applied ANN approach for prediction of the parabolic through collector performance based on the experimental data. They concluded a good agreement between the prediction performances and real data under different parameters. Kalogirou et al. [8] applied ANN methodology for prediction of the rising temperature and gained useful energy by a solar domestic water heating. They concluded that the ANN approach can successfully predict the rising temperature and the heat gained by the solar system.

Kalogirou [9] presented a review of the application of the ANN in renewable energy systems. This paper shows that the ANN approach accounts for the good method for modeling, design, optimization, and performance prediction in the solar systems.

Sözen et al. [10] estimated the thermal efficiency of flat plate solar collectors using ANN methodology. Kalogirou [11] presented two of the most important artificial intelligence techniques including ANN and GA for applications in solar energy systems. Yaïci and Entchev [12] modeled a solar thermal energy system with ANN methodology that the solar system was used for domestic hot water and space heating. The results reveal that the ANN methodology is an effective and accurate approach for prediction of the performance system. Kalogirou et al. [13] predicted the performance of a large solar system with application of the ANN methodology. They resulted that there were a good agreement between the predicted performance and experimental results. Amirkhani et al. [14] used ANN and ANFID modeling for prediction of the performance in a solar chimney power plant based on the experimental data. The results show that predicted performance of the solar chimney power plants by such methods can accuracy accept in comparing with the experimental results with less computational cost.

It can be seen from literature review that there is no research that used ANN approach for prediction of the parabolic dish collector with the cavity receiver. On the other hand, improving the performance and optimization structure of the thermal power system with less consumption cost and time approach such as ANN methodology is an interesting subject. Therefore, the current study is original and significantly important. In this study the thermal performance of a parabolic dish concentrator with a rectangular-tubular cavity receiver was investigated. The thermal oil was used as the working fluid in the solar collector system. The performance of the cavity receiver was studied in two ways: (i) the numerical modeling method and (ii) ANNs methodology. In this study, two variable parameters were considered: (i) the different tube diameters equal to $5,10,22$, and $35 \mathrm{~mm}$ and (ii) the different cavity depths equal to $0.5 a$, $0.75 a, 1 a, 1.5 a$, and $2 a$.

The purpose of this study was investigated, the accuracy of the ANN methodology for thermal performance prediction of the cavity receiver in different amount the cavity depth, and the diameter of tube. The main benefit of the ANN method compared to the numerical modeling method was the time and cost saving. The procedure of determining the optimum structure of cavity receiver is depicted in Figure 1.

\section{Models and description}

\subsection{General}

The parabolic dish concentrator with a rectangular cavity receiver was used for absorbing the solar irradiation by the tube walls of the cavity receiver. The receiver presented in this work is a rectangular open-cavity receiver constructed with a coated copper tube through which the thermal oil flows (Fig. 2). The thermal oil as the solar working fluid was entered from the tube at the bottom of the receiver and the heated working fluid was exited from the tube at the top of the cavity receiver. The absorbed solar heat was transferred to the thermal oil. The receiver tube forms the inner wall of the open-cavity receiver.

\subsubsection{Receiver thermal modeling method}

In this study, an accuracy thermal modeling method was applied based on the proposed method in [6]. In this method, the tubular cavity receiver was divided into a 


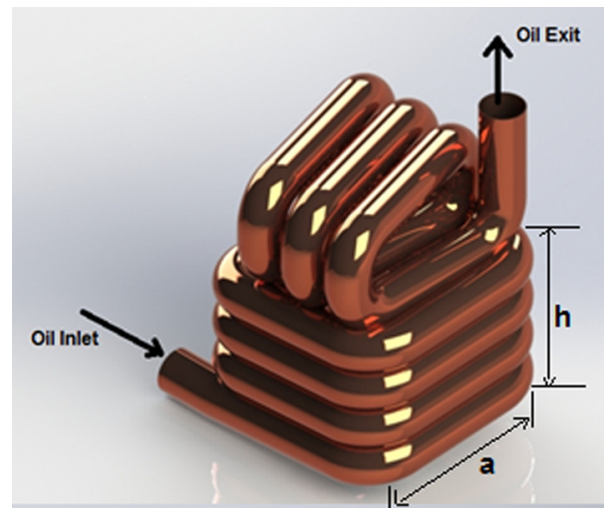

Fig. 2. A square prismatic open-cavity solar receiver.

number of sections along the inner tube of the cavity receiver as following:

$$
N=4\left(\frac{h}{d}\right)+\frac{a}{d}
$$

Then the surface temperature $\left(T_{s, n}\right)$ and the net heat transfer rates $\left(\dot{Q}_{n e t, n}\right)$ at different elements of the tube were determined by solving equations (2) and (3) using the Newton-Raphson method [6]:

$$
\dot{Q}_{n e t, n}=\frac{\left(T_{s, n}-\sum_{i=1}^{n-1}\left(\frac{\dot{Q}_{n e t, i}}{\dot{m}_{\text {oil }} c_{p 0}}\right)-T_{\text {inlet }, 0}\right)}{\left(\frac{1}{h A_{n}^{\prime}}+\frac{1}{2 \dot{m}_{\text {oil }} c_{p 0}}\right)}
$$

and

$$
\begin{aligned}
\dot{Q}_{n e t, n} & =\dot{Q}_{n}^{*}-A_{n} \varepsilon_{n} \sigma\left(T_{s, n}^{4}\right)+A_{n} \sum_{j=1}^{N} F_{n-j} \varepsilon_{j} \sigma\left(T_{s, n}^{4}\right) \\
& -A_{n} \varepsilon_{n} \sigma F_{n-\infty} T_{\infty}^{4}-A_{n}\left(m_{2} T_{s, n}+c_{2}\right) \\
& -\frac{A_{n}}{R_{\text {cond }}}\left(T_{s, n}-T_{\infty}\right)
\end{aligned}
$$

After calculation of the net heat gained $\left(\dot{Q}_{n}\right)$ by each element tube along the tubular cavity receiver, the outlet temperature of the working fluid for each element tube can be calculated as following:

$$
T_{\text {out }, n}=T_{\text {out }, n-1}+\frac{\dot{Q}_{n}}{\dot{m}_{\text {oil }} c_{p 0}}
$$

where $T_{\text {out, } n}$ is the outlet temperature of the working fluid for each element tube and $T_{\text {out }, n-1}$ is the inlet temperature of the working fluid for it.

The collector efficiency was defined as following [15]:

$$
\eta_{\text {col }}=\frac{\dot{m}_{\text {oil }} c_{p 0}\left(T_{\text {outlet }}-T_{\text {inlet }}\right)}{\dot{Q}_{\text {solar }}}=\frac{\dot{m}_{\text {oil }} c_{p 0}\left(T_{\text {outlet }}-T_{\text {inlet }}\right)}{\left(\frac{\pi D_{\text {dish }}^{2}}{4}\right) \dot{I}_{\text {sun }}}
$$

where $T_{\text {inlet }}$ is the cavity inlet temperature of the working fluid that is assumed to be equal to $50{ }^{\circ} \mathrm{C}$ in this study and $T_{\text {outlet }}$ is the cavity outlet temperature of the working fluid that is equal to the outlet temperature of the last element tube of the tubular cavity receiver.
Table 1. Thermal analysis parameters.

\begin{tabular}{ll}
\hline Assumed parameters & Assumed data \\
\hline $\begin{array}{l}\text { Length of the cavity } \\
\text { receiver }(a)\end{array}$ & $0.125(\mathrm{~m})$ \\
$\begin{array}{l}\text { Inlet temperature of the } \\
\text { thermal oil }\left(T_{\text {inlet }, 0}\right)\end{array}$ & $50\left({ }^{\circ} \mathrm{C}\right)$ \\
$\begin{array}{l}\text { Mass flow rate of the } \\
\text { thermal oil }\left(\dot{m}_{\text {oil }}\right)\end{array}$ & $0.01\left(\mathrm{~kg} \mathrm{~s}^{-1}\right)$ \\
$\begin{array}{l}\text { Average surrounding } \\
\text { temperature }\left(T_{\text {amb }}\right)\end{array}$ & $26\left({ }^{\circ} \mathrm{C}\right)$ \\
$\begin{array}{l}\text { Atmospheric pressure }(P) \\
\text { Emissivity of the black } \\
\text { chromium coating }(\varepsilon)\end{array}$ & $84(\mathrm{kPa})$ \\
$\begin{array}{l}\text { Dish concentrator } \\
\text { diameter }(D)\end{array}$ & 0.2 \\
$\begin{array}{l}\text { Variable parameters } \\
\text { Tube diameters }(d)\end{array}$ & $1.8(\mathrm{~m})$ \\
Cavity depths $(h)$ & Investigated data \\
& 10,22, and $35 \mathrm{~mm}$ \\
\hline
\end{tabular}

The receiver surface temperature at different elements of the tube and the net heat transfer rate depend on the aperture size, the height of the cavity receiver, the mass flow rate of the solar working fluid, the receiver tube diameter and the working fluid inlet temperature. Thermal analyses parameters and their value are shown in Table 1. The thermal characteristics of the thermal Behran oil are obtained by [16].

\subsection{ANN description}

ANNs are a simulation of the manner nerve cell (neurons) in the biological central nervous system. The important feature of the ANNs is that it could learn, memorize and create relationships among data [9]. The optimum weight of the network neurons was found by the ANN using recorded data and the output variables were predicted base on this optimum found weight of the network neurons [17]. In Figure 3, the method of the ANN output computing is illustrated.

In this study, ANN modeling was carried out in two stages. First, we applied the ANN approach for outlet temperature of the working fluid for each tube element. Second, the collector efficiencies as a thermal performance parameter of the cavity receiver were calculated (Eq. (5)) based on the predicted outlet temperature in the first stage for each condition prediction (Fig. 4).Figures 5 and 6 describe the details of the utilized ANN approach for $h$ and $d$ as the variable parameters, respectively. These figures illustrate the general methods for assuming of the training and evaluation values based on the numerical modeling results. It has to be mentioned that the numerical modeling results after validation with the experimental results were used for training and testing of ANN approach for different variable parameters. 


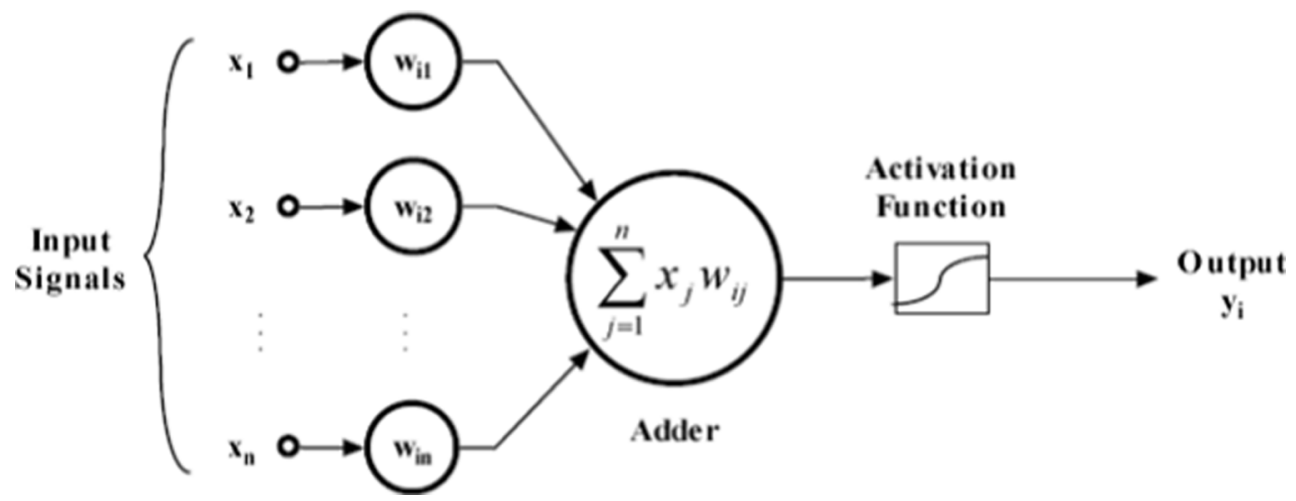

Fig. 3. Output computing in ANN [18].

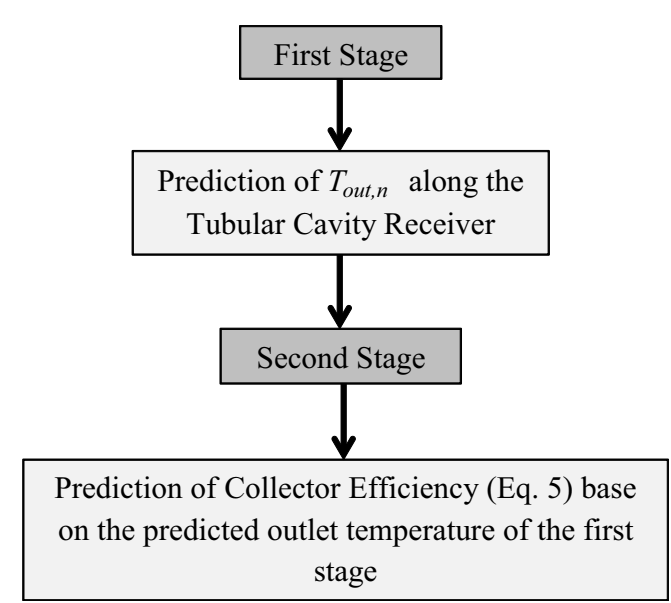

Fig. 4. Stages of the ANN prediction of the collector performance for each considered variable parameter.

In equation (6) the target value, $o_{j}$ is the outcome of the ANN model. The parameter $t_{j}$ stands for the estimated target from the ANN approach for an assumed input while $o_{j}$ represents the desired target (i.e. measured data) from the similar input that has been generated by the setup. The $R^{2}$ value varies between 0 and $+1 . R^{2}$ values near to +1 represent a robust positive linear correlation, while $R^{2}$ values near to 0 represent very weak correlation $[19,20]$. This value can be determined according to the below formula [21-28]:

$$
R^{2}=1-\left(\frac{\sum_{j}\left(t_{j}-o_{j}\right)^{2}}{\sum_{j}\left(o_{j}\right)^{2}}\right)
$$

The network is trained by optimization and updating the weights for each node until the output gets as close as possible to the real target. The MSE of the network is given as [21-31]:

$$
M S E=\frac{1}{2} \sum_{k=1}^{G} \sum_{j=1}^{m}\left(o_{j}(k)-t_{j}(k)\right)^{2}
$$

\section{Results and discussion}

\subsection{Validation of the numerical simulation with experimental results}

It has to be mentioned that the numerical results were validated with the experimental results in [32]. The detail of the numerical method, results and validation of the results were explained in [32].

\subsection{Comparing the ANN prediction with numerical results}

3.2.1 Sensitivity analysis of the hidden neurons number

Before grappling with details of the gained results of the proposed intelligent based model, which called "ANN", sensitivity analysis of the addressed model versus number of hidden neurons should be demonstrated. Figures 7 and 8 describe the effect of the number of hidden neurons in hidden layer of the developed network approach on the correlation coefficient $\left(R^{2}\right)$ and mean square error (MSE) of the proposed ANN model of the developed approach for the torque for the depth of the cavity and for the tube diameter as the variable, respectively. It can be seen from Figure 7 that the maximum correlation coefficient $\left(R^{2}\right)$ is gained when "hidden neurons $\geq 100$ " while the minimum correlation coefficient $\left(R^{2}\right)$ occurred when "hidden neurons $=1$ " and the minimum value of MSE occurred when "hidden neurons $=110$ " while maximum value of MSE is obtained when "hidden neurons = 1 " in the ANN model for the depth of the cavity as the variable. Then it can be resulted that the optimum number of the hidden neurons for the depth of the cavity was found equal to 110 , which has the maximum $R^{2}$ and minimum MSE. So hidden neurons equal to 110 will be applied for further analysis of the depth of the cavity as the variable.

While it can be seen from Figure 8 that the maximum correlation coefficient $\left(R^{2}\right)$ is gained when "hidden neurons = 30 ", the minimum correlation coefficient $\left(R^{2}\right)$ occurred when "hidden neurons $=188$ ". One of the minimum values of MSE occurred when "hidden neurons $=30$ ", maximum value of MSE is obtained when "hidden neurons $=1$ " in the ANN model for the tube diameter as the variable. Then it can be resulted that the optimum number of the hidden neurons for the tube diameter as the variable was 30 , which has the 


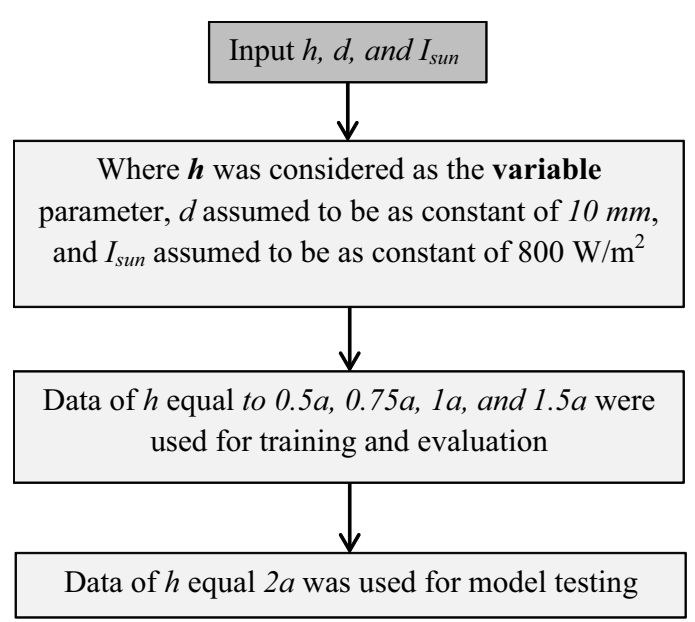

Fig. 5. The procedure of the ANN method for the cavity depth as the variable.

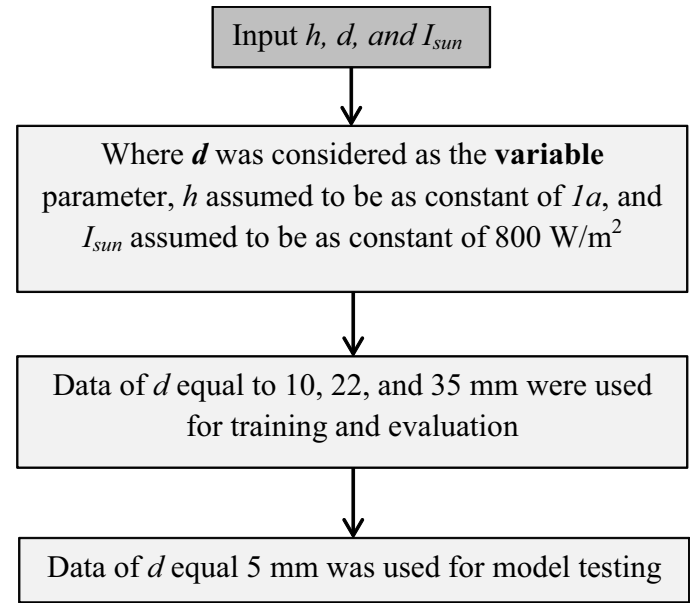

Fig. 6. The procedure of the ANN method for the tube diameter as the variable.

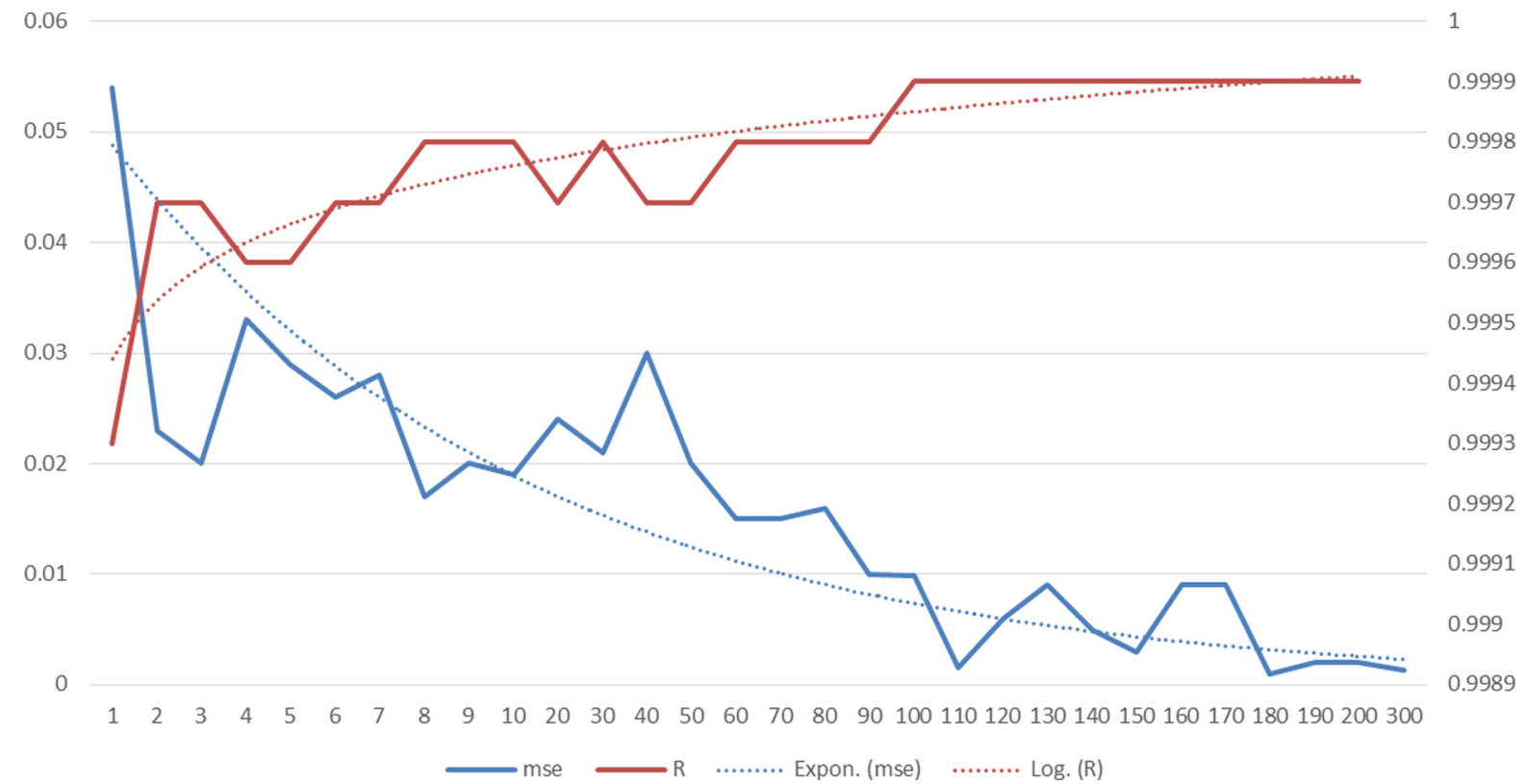

Fig. 7. Variation of correlation coefficient and the MSE against number of hidden neurons for torque determination for the depth of the cavity as the variable.

maximum $R^{2}$ and minimum MSE. So hidden neurons equal to 30 will be applied for further analysis of the tube diameter as the variable.

\subsubsection{Effect of the tube diameters}

Figure 9 shows the accuracy of the ANN results compared to the numerical modeling results for the outlet temperature of the working fluid for each element along the inner tube of the cavity receiver in different tube diameters. Figure 9a depicts the accuracy of the ANN output compared to the numerical modeling results. Figure $9 \mathrm{~b}$ displays a comparison of the ANN and the numerical modeling results of the outlet temperature of the working fluid along the inner tube of the cavity receiver.
It can be seen from Figure $9 \mathrm{a}$ and b that there is a good agreement with $R^{2}=0.99$ between the ANN results and the numerical modeling results for the outlet temperature of the working fluid for each element of the tubular cavity receiver.

\subsubsection{Effect of the cavity depths}

Figure 10 shows the accuracy of the ANN results compared to the numerical modeling results for the outlet temperature of the working fluid for each element along the inner tube of the cavity receiver in different cavity depths. Figure 10a depicts the accuracy of the ANN output compared to the numerical modeling results. Figure 10b displays a comparison of the ANN and the numerical modeling results of the outlet temperature of the working fluid along the inner tube of the cavity receiver. 


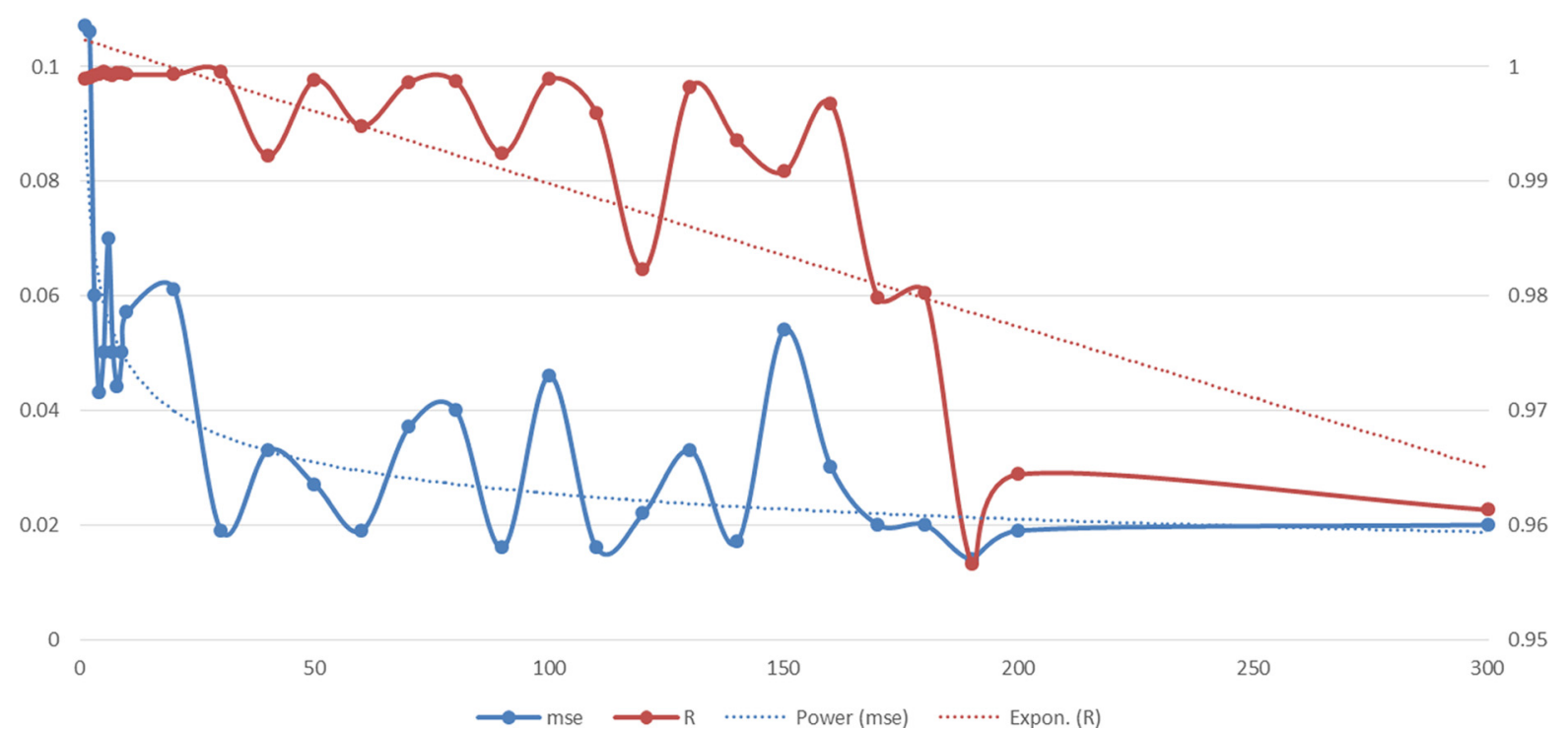

Fig. 8. Variation of correlation coefficient and the MSE against number of hidden neurons for torque determination for the tube diameter as the variable.
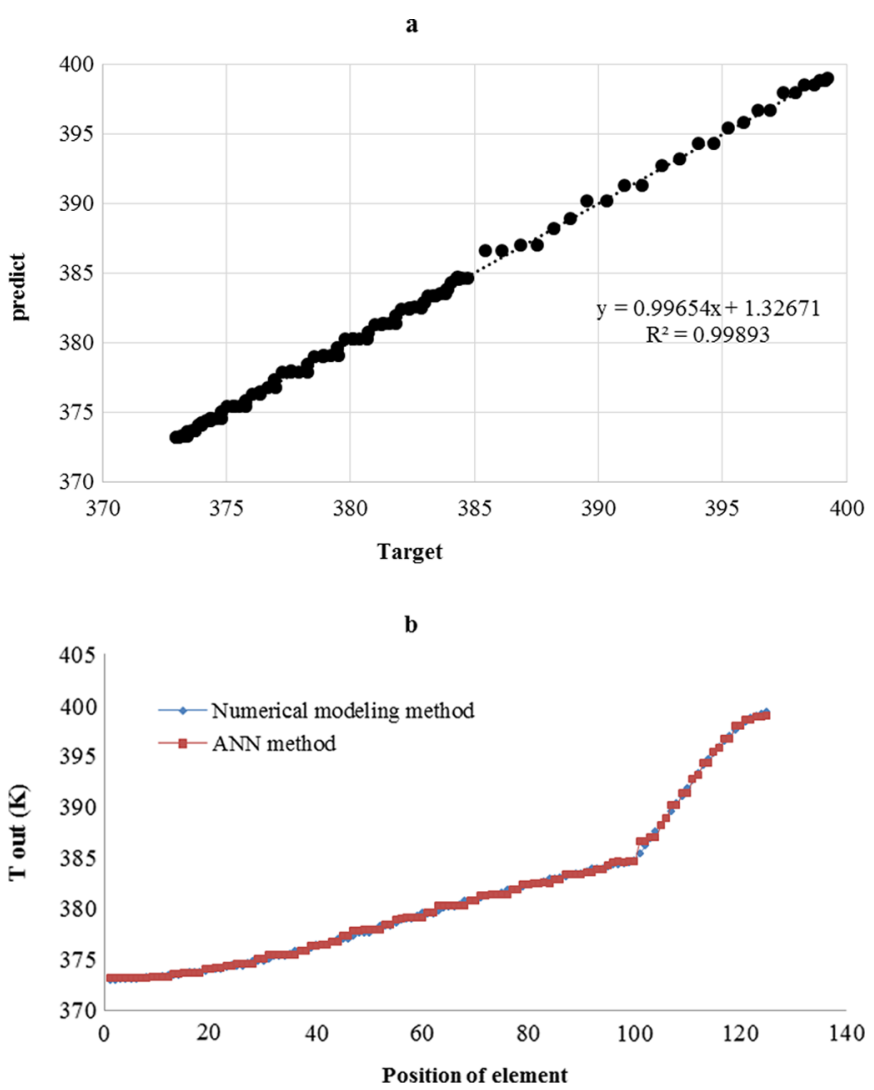

Fig. 9. (a) Accuracy of ANN results compared with the numerical modeling results and (b) comparison of the ANN results and the numerical modeling results of the working fluid outlet temperature in different tube diameters.
It can be seen from Figure 10a and b that there is a good agreement with $R^{2}=0.99$ between the ANN results and the numerical modeling results for the outlet temperature of the working fluid for each element of the tubular cavity receiver.

\subsubsection{Collector efficiency}

Table 2 shows a comparison of the collector efficiency which was calculated by the thermal modeling method and predicted by the ANN method for $d$ and $h$ as the variable parameters. It can be resulted from Table 2 that the collector efficiency predicted by the ANN method can compare with the numerical modeling results. On the other hand, using the ANN method for prediction of the collector efficiency can save the time and cost for determining the optimum structure of the cavity receiver.

\section{Conclusion}

The parabolic dish concentrator with a rectangular cavity receiver was investigated in this study. The dish concentrator diameter of $1.8 \mathrm{~m}$ with reflectivity of $84 \%$ and the rectangular cavity receiver with length of the aperture of $0.125 \mathrm{~m}$ were studied. The thermal oil was used as the working fluid. In this study, the performance of the cavity receiver was calculated in different methods such as a numerical modeling, based on the thermal modeling of the cavity receiver, and ANN method for the performance prediction. The purpose of this study was calculation of the optimum structure of the cavity receiver for achieving higher thermal performance by ANN approach as an accuracy approach with the less consumption of the cost and time. In the numerical modeling the performance of the cavity was calculated at the different depths, different diameter of tube, 

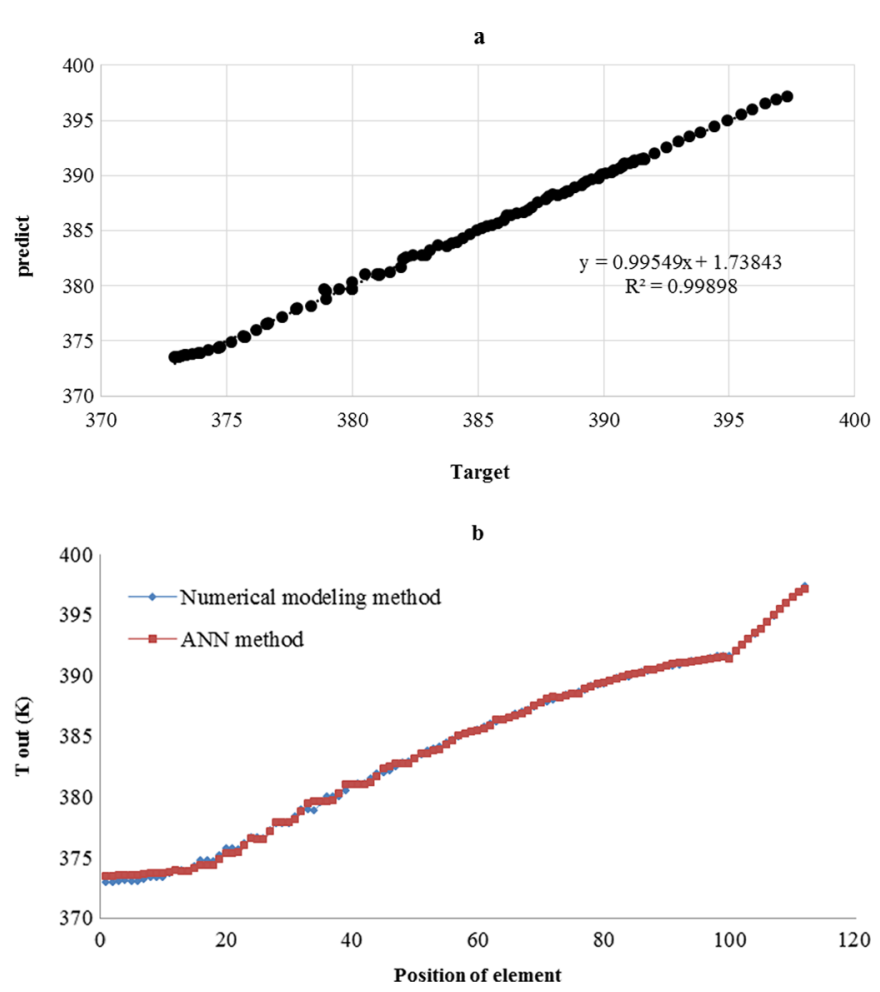

Fig. 10. (a) Accuracy of ANN results compared with the numerical modeling results and (b) comparison of the ANN results and the numerical modeling results of the working fluid outlet temperature in different cavity depths.

Table 2. Comparison of the collector efficiency calculated by the thermal modeling method and predicted by the ANN method.

\begin{tabular}{lll}
\hline Variable & Numerical modeling method & ANN method \\
\hline$d$ & 0.57 & 0.53 \\
$h$ & 0.53 & 0.50 \\
\hline
\end{tabular}

and different solar intensity. And the numerical modeling results were validated with experimental results. Then the resulted of the numerical modeling was used for training of the ANN method and finally prediction of the thermal performance of the cavity was conducted by this method. The main benefit of the ANN method was that the numerical modeling method saved the time and cost. The results obtained were as following:

- there was a good agreement with $R^{2}=0.99$ between the predicted results of ANN and the calculated numerical modeling results for the outlet temperature of the working fluid for each tube element of the tubular cavity receiver, when the tube diameter and the cavity depth were investigated as the variable parameters;

- the collector efficiency predicted by the ANN method can be compared to the numerical modeling results. On the other hand, using the ANN method for prediction of the collector efficiency can save the time and cost of the calculation for determining the optimum structure of the cavity receiver.

\section{Nomenclature}

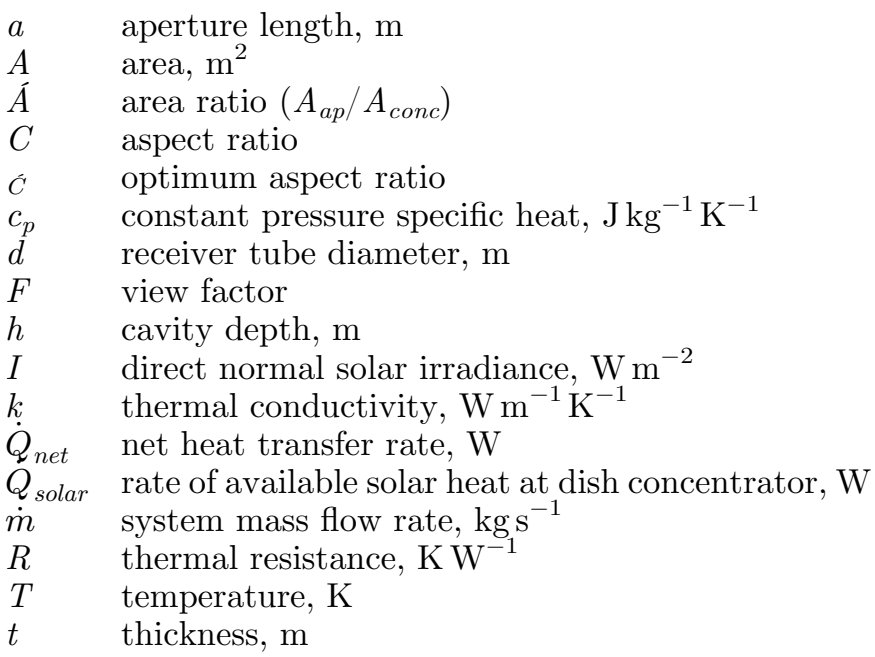

\section{Greek symbols}

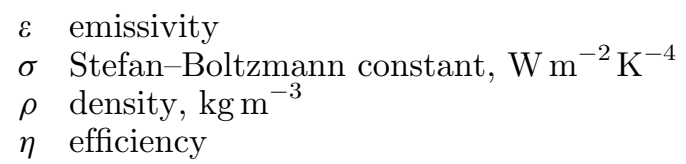

\section{Subscripts}

$0 \quad$ initial inlet to receiver

ap aperture

col overall for the collector

dish dish concentrator

$f \quad$ fluid

inlet at the inlet

ins insulation

$n \quad$ tube section number

$s \quad$ surface

outlet at the outlet

total total

$\infty \quad$ environment

\section{References}

[1] S.A. Kalogirou, Solar thermal collectors and applications, Prog. Energy Combust. 30 (2004) 231-295

[2] J.A. Harris, T.G. Lenz, Thermal performance of solar concentrator/cavity receiver systems, Solar Energy 34 (1985) 135-142

[3] A.M. Clausing, An analysis of convective losses from cavity solar central receiver, Solar Energy 27 (1981) 295-300

[4] P. Le Quere, F. Penot, M. Mirenayat, Experimental study of heat loss through natural convection from an isothermal cubic open cavity, Sandia Laboratory Report, 1981, SAN D81-8014

[5] W. Huang, F. Huang, P. Hu, Z. Chen, Prediction and optimization of the performance of parabolic solar dish concentrator with sphere receiver using analytical function, Renew. Energy 53 (2013) 18-26 
[6] W.G. Le Roux, T. Bello-Ochende, J.P. Meyer, The efficiency of an open-cavity tubular solar receiver for a small-scale solar thermal Brayton cycle, Energy Convers. Manag. 84 (2014) $457-470$

[7] S.A. Kalogirou, C.C. Neocleous, C.N. Schizas, Artificial neural networks in modeling the heat-up response of a solar steam generation plant, in: Proceedings of the International Conference EANN'96, 1996, pp. 1-4

[8] S.A. Kalogirou, S. Panteliou, A. Dentsoras, Modeling of solar domestic water heating systems using artificial neural networks, Solar Energy 65 (1999) 335-342

[9] S.A. Kalogirou, Artificial neural networks in renewable energy systems applications: a review, Renew. Sustain. Energy Rev. 5 (2001) 373-401

[10] A. Sözen, T. Menlik, S. Ünvar, Determination of efficiency of flat-plate solar collectors using neural network approach, Exp. Syst. Appl. 35 (2008) 1533-1539

[11] S.A. Kalogirou, Artificial neural networks and genetic algorithms for the modeling, simulation, and performance prediction of solar energy systems, in: Assessment and simulation tools for sustainable energy systems, Springer, New Work, 2013, pp. 225-245

[12] W. Yaïci, E. Entchev, Performance prediction of a solar thermal energy system using artificial neural networks, Appl. Therm. Eng. 73 (2014) 1348-1359

[13] S.A. Kalogirou, E. Mathioulakis, V. Belessiotis, Artificial neural networks for the performance prediction of large solar systems, Renew. Energy 63 (2014) 90-97

[14] S. Amirkhani, Sh. Nasirivatan, A.B. Kasaeian, A. Hajinezhad, ANN and ANFIS models to predict the performance of solar chimney power plants, Renew. Energy 83 (2015) 597-607

[15] Y.A. Cengel, Heat and mass transfer, 3rd ed., McGrawHill, Nevada, 2006

[16] A. Baghernejad, M. Yaghoubi, Thermoeconomic methodology of analysis and optimization of a hybrid solar thermal power plant, Int. J. Green Energy 10 (2013) 588-609

[17] S.A. Kalogirou, Applications of artificial neural networks for energy systems, Appl. Energy 67 (2000) 17-35

[18] A.K. Tripathy, S. Mohapatra, S. Beura, G. Pradhan, Weather forecasting using ANN and PSO, Int. J. Scient. Eng. Res. 2 (2011) 1-5

[19] Y.O. Ozgoren, S. Cetinkaya, S. Sarıdemir, A. Cicek, F. Kara, Predictive modeling of performance of a helium charged Stirling engine using an artificial neural network, Energy Convers. Manage. 67 (2013) 357-368
[20] C. Sayin, H.M. Ertunc, M. Hosoz, I. Kilicaslan, M. Canakci, Performance and exhaust emissions of a gasoline engine using artificial neural network, Appl. Therm. Eng. 27 (2007) 46-54

[21] K. Hornick, M. Stinchcombe, H. White, Neural Network 2 (1989) 359-366

[22] M. Brown, C. Harris, Neural fuzzy adaptive modeling and control, Prentice-Hall, Englewood Cliffs, NJ, 1994

[23] S. Zendehboudi, M.A. Ahmadi, A. Bahadori, A. Shafiei, T. Babadagli, A developed smart technique to predict minimum miscible pressure - EOR implication, Canad. J. Chem. Eng. 91 (2013) 1-13

[24] S. Zendehboudi, M.A. Ahmadi, O. Mohammadzadeh, A. Bahadori, I. Chatzis, Thermodynamic investigation of asphaltene precipitation during primary oil production, laboratory and smart technique, Ind. Eng. Chem. Res., 2017, doi: $10.1021 /$ ie 301949 c

[25] M.H. Ahmadi, S.S. Ghare Aghaj, A. Nazeri, Prediction of power in solar Stirling heat engine by using neural network based on hybrid genetic algorithm and particle swarm optimization, Neural Comput. Appl. 22 (2013) 1141-1150

[26] M.H. Ahmadi, M.A. Ahmadi, S.A. Sadatsakkak, M. Feidt, Connectionist intelligent model estimates output power and torque of Stirling engine, Renew. Sustain. Energy Rev. 50 (2015) 871-883

[27] M.H. Ahmadi, M.A. Ahmadi, M. Mehrpooya, M.A. Rosen, Using GMDH neural networks to model the power and torque of a Stirling engine, Sustainability 7 (2015) 2243-2255

[28] S.M. Pourkiaei, M.H. Ahmadi, S.M. Hasheminejad, Modeling and experimental verification of a $25 \mathrm{~W}$ fabricated PEM fuel cell by parametric and GMDH-type neural network, Mech. Indust. 17 (2016) 105

[29] S.A. Sadatsakkak, M.H. Ahmadi, M.A. Ahmadi, Implementation of artificial neural-networks to model the performance parameters of Stirling engine, Mech. Indust. 17 (2016) 307

[30] M.H. Ahmadi, M.A. Ahmadi, M. Ashouri, F.R. Astaraei, R. Ghasempour, F. Aloui, Prediction of performance of Stirling engine using least squares support machine technique, Mech. Indust. 17 (2016) 506

[31] A. Kasaeian, M. Mehrpooya, M. Aghaie, M.H. Ahmadi, Solar radiation prediction based on ICA and HGAPSO for Kuhin City, Iran, Mech. Indust. 17 (2016) 509

[32] R. Loni, A.B. Kasaeian, E.A. Asli-Ardeh, B. Ghobadian, W.G. Le Roux, Performance study of a solar-assisted organic Rankine cycle using a dish mounted rectangular-cavity tubular solar receiver, Appl. Therm. Eng. 108 (2016) 1298-1309

Cite this article as: R. Loni, A. Kasaeian, K. Shahverdi, E. Askari Asli-Ardeh, B. Ghobadian, M.H. Ahmadi, ANN model to predict the performance of parabolic dish collector with tubular cavity receiver, Mechanics \& Industry 18, 408 (2017) 